\title{
Politics, culture and class in the french Revolution
}

\section{Annie Duprat}

\section{(2) OpenEdition}

\section{Journals}

Édition électronique

URL : https://journals.openedition.org/ahrf/1967

DOI : 10.4000/ahrf.1967

ISSN : 1952-403X

Éditeur :

Armand Colin, Société des études robespierristes

Édition imprimée

Date de publication : 1 décembre 2005

Pagination : 265-267

ISSN : 0003-4436

\section{Référence électronique}

Annie Duprat, "Politics, culture and class in the french Revolution », Annales historiques de la Révolution française [En ligne], 342 I octobre-décembre 2005, mis en ligne le 05 avril 2006, consulté le 23 avril 2022. URL : http://journals.openedition.org/ahrf/1967 ; DOI : https://doi.org/10.4000/ahrf.1967

Ce document a été généré automatiquement le 23 avril 2022.

Tous droits réservés 


\title{
Politics, culture and class in the french Revolution
}

\author{
Annie Duprat
}

\section{RÉFÉRENCE}

Lynn Hunt, Politics, culture and class in the french Revolution, Berkeley, Londres et Los

Angeles, University of California Press, 2004, 252 p., ISBN 0-520-24156-8, 21.95 \$

1 Alors que les publications universitaires portant sur l'histoire du XVIII siècle européen deviennent de plus en plus rares de l'autre côté de l'Atlantique, saluons la réédition, pour le 20e anniversaire de sa première publication, de cet ouvrage pionnier de Lynn Hunt. En effet, si l'on se replace à la fin des années 1970, comme nous y invite la préface à la nouvelle édition, on comprend mieux le projet de l'auteur qui déclare avoir voulu vérifier la pertinence des analyses marxistes sur le rôle des marchands et des entrepreneurs, la bourgeoisie donc, dans le déroulement de la Révolution. Ayant repris la réflexion grâce à une très imposante bibliographie, française et américaine, ancienne (on retrouvera fréquemment Tocqueville) et récente à l'époque (Martyn Lyons, Revolution in Toulouse : an essay on provincial terrorism, Berne, 1978, ou Theda Skocpol, State and social Revolutions, Cambridge, 1979), et à des dossiers d'une histoire sociale mêlant approches politiques, économiques et culturelles qu'elle venait de travailler (Revolution and Urban Politics in Provincial France, 1978), elle reconnaît que, si elle rencontre bien ces marchands et manufacturiers dans la vie en Révolution des villes françaises, elle ne peut pas établir de modèle ni de système de leur influence sur les événements : dans certains lieux ils en gagnent, dans d'autres ils en perdent, dans d'autres enfin ils n'ont jamais véritablement joué de rôle. Ayant décidé de lier ensemble l'étude de tous les autres facteurs déterminants de la transformation de la société (relations inter-personnelles et conflits pré-existants à la Révolution, rôle des loges maçonniques, des clubs révolutionnaires, de la diffusion des idées par la presse, par les livres et par l'enseignement), elle conclut à la nécessité de prendre en compte toutes les composantes culturelles dans l'étude d'une société. La préface se termine par un bref 
rappel de la situation des études historiques sur la Révolution française au moment du Bicentenaire qui voyait les analyses de Furet à leur zénith et l'école marxiste à son nadir, pour observer depuis le développement de critiques à l'encontre d'un «toutculturel ", qui serait aussi appauvrissant que le "tout-structurel » économique, ou encore la quasi-disparition de l'idée selon laquelle la Terreur serait la matrice des totalitarismes $\mathrm{du} \mathrm{xx}^{\mathrm{e}}$ siècle. Mais il demeure que l'étude des relations croisées entre politique et société reste une question plus importante que jamais, aux yeux de Lynn Hunt. À part cette très brève préface (qui comporte quelques notes), le livre édité en 2004 est une stricte réimpression de la version de 1984, sans ajout de notes ni de bibliographie, ce que l'on peut regretter étant donné l'importance des publications ultérieures, dont un certain nombre ont tiré profit des hypothèses de travail de l'historienne américaine. Rappelons également que Politics, culture and class in the french Revolution est composé de six chapitres, certains ayant déjà fait l'objet d'une publication (à l'identique ou dans une version qui a été revue et augmentée) dans History workshop journal, pour le premier chapitre, "the Rhetoric of Revolution in France», et Representations pour le troisième, «Hercule and the Radical Image of the French Revolution », les tables et annexes ayant été publiées précédemment dans The journal of interdisciplinary History.

2 Après avoir repris dans une introduction programmatique (p. 1-16) la question de l'interprétation de la Révolution, Lynn Hunt divise son étude en deux grandes parties égales, dont chacun des titres annonce le projet d'ensemble, «The Poétics of Power » et "The Sociology of Politics». Plaçant sa réflexion sous l'exergue d'un Rousseau qui affirme que tout est politique et/ou que tout tient à la politique, elle montre que dans le déroulement de leur révolution, les Français ne se sont pas uniquement préoccupés de débattre de la forme et de la nature de leur gouvernement, mais aussi des pratiques de citoyenneté ou de la politique de la langue, qui attire l'attention de Grégoire mais aussi des clubs patriotiques. Lynn Hunt rend ici hommage aux travaux de Mona Ozouf et de Maurice Agulhon. Effectivement, c'est d'abord de la question linguistique que traite le premier chapitre, puisqu'elle y reprend les exemples figurant dans l'écrit célèbre de La Harpe, Du fanatisme dans la langue révolutionnaire, du remplacement du vocabulaire d'Ancien Régime par un vocabulaire régénéré et patriotique ("avocats" et "procureurs » devenus « hommes de lois », «impôts » devenus "contributions », les prénoms chrétiens remplacés par des prénoms révolutionnaires...); elle étudie également les titres de certains journaux comme Le dénonciateur patriotique, pour montrer, à la suite de Furet, l'obsession du complot, ou encore l'ensemble des productions culturelles pour pointer l'importance des figures féminines et l'absence de la figure du père dans ce monde en chamboulement complet (rappelons que ce dernier aspect sera le pivot de son Histoire familiale de la Révolution française, publiée aux ÉtatsUnis en 1992). Le chapitre suivant, consacré aux formes symboliques de la pratique du pouvoir s'intéresse aux fonctions du costume (cocarde et bonnet surtout) et de certains rituels très forts comme les fêtes patriotiques (la plantation des arbres de la Liberté, la fête de la déesse Raison de novembre 1793) pour conclure que le pouvoir des autorités étatiques s'installe dans la population non pas tant pour des raisons idéologiques que par la multiplication de toutes ces cérémonies qui mettent en jeu des fêtes, des costumes, des chants (des images également, mais cet aspect, qui figure dans le livre par ses 21 illustrations, n'est guère étudié par l'auteur). Mais il existe toujours une tension entre deux nécessités, la transparence et la pédagogie révolutionnaires, dont Germaine de Staël (Des circonstances actuelles qui peuvent terminer la Révolution et des 
principes qui doivent fonder la république en France) avait trouvé l'explication dans l'idée que la Révolution était arrivée en France avant les Lumières qui auraient pu la fonder. Le troisième chapitre, qui porte sur "l'imagerie du radicalisme » est sans doute celui dont la postérité a été la plus féconde. L'auteur s'y interroge sur la politique symbolique de la représentation à travers l'étude des débats sur le sceau (des Archives Nationales puis de l'État), entre la figure féminine, qui correspond aux iconologies traditionnelles, et celle d'Hercule, dont le projet apparait après la chute des Girondins. Parcourant la question d'Hercule depuis les Hercule gaulois des entrées des rois de France de la Renaissance jusqu'au bébé Hercule américain protégé du léopard anglais par une déesse France sur une médaille de Dupré, Lynn Hunt nous conduit à réexaminer la gravure des Révolutions de Paris, «Le peuple mangeur de rois », qui n'est pas une figure allégorique car elle n'a pas de contenu métaphorique; le géant qui représente le peuple correspond ici au degré zéro de la représentation, celui de la force brute. Le projet de David d'une statue du peuple portant des écrits sur le corps, qui devait être érigée sur tous les points élevés de la république, est assez rapidement traité avant l'observation finale sur la disparition des Hercule vers 1799, avant le passage à la personnalisation du pouvoir en la personne de Bonaparte. Aucun sceau n'a pu être fixé parce que la Révolution est elle-même un flux.

3 La seconde partie commence par un chapitre sur la " géopolitique de la Révolution »; l'étude introduit le cadre symbolique déjà décrit (bonnet, arbres, serments, fêtes etc.) et étudie les résultats électoraux dans les provinces, pour s'interroger sur les conditions locales de l'acculturation révolutionnaire. Le postulat de l'auteur est de voir la part de la résistance (ou de l'adhésion) à la Révolution qui relève des hommes plutôt que des idées. Il serait intéressant de confronter ce chapitre à tous les travaux publiés depuis (Michel Vovelle, La découverte de la politique : géopolitique de la Révolution française, La Découverte, 1993). Le chapitre suivant, qui porte sur «Les nouvelles classes de la Révolution ", est un examen historiographique des travaux universitaires portant sur l'évolution des groupes sociaux et des parcours biographiques individuels, tandis que le dernier chapitre relève davantage de l'histoire culturelle au sens où nous l'entendons aujourd'hui. Il s'agit d'une étude sur le rôle des "outsiders» (terme difficilement traduisible, car ce ne sont pas seulement les « Rousseau du ruisseau », encore moins des marginaux, mais peut-être tous les vecteurs de l'opinion, éclairée ou non), les libraires et les réseaux politiques. Comme le chapitre 3, il s'agit d'une étude passionnante et destinée à un avenir fécond, qui considère la Révolution comme un rite de passage dont le point final n'est jamais connu. Les nouvelles valeurs qui sont affirmées n'ont pas le temps de s'installer, alors que les discours ne cessent de désigner ce qui est neuf ou ce qui est vieux.

4 Dans sa conclusion, "Révolution dans la culture ", Lynn Hunt pose la question des débats historiographiques sur la Révolution française qui se présentent toujours de manière tranchée, en particulier dans la description des violences populaires. Comparant cette histoire avec celle de l'Angleterre et des États-Unis, qui ont très tôt choisi de se méfier des foules et de la démocratie directe, elle trouve une partie de l'explication dans les relations entre la monarchie, la noblesse et le parlement, ce dernier se posant comme le garant des libertés du peuple. Le tiers état, massivement composé de robins, s'est logiquement appuyé, dès 1789 , sur la plèbe urbaine. Reprenant les analyses de Tocqueville, Lynn Hunt réaffirme que la Terreur ne peut pas se comprendre si l'on ignore tout ce qui l'a précédée, tandis que 1799 ne peut pas être simplement vu comme le point terminal d'une série de circonstances, mais doit 
s'expliquer par la faiblesse de la culture révolutionnaire en France. Bonaparte a bien compris l'importance des enjeux symboliques de la période révolutionnaire puisqu'il continue à les utiliser au moins jusqu'en 1807.

5 Ce livre, qui marque un jalon important dans l'historiographie récente de la Révolution française et procure une grande satisfaction intellectuelle, mérite d'être rapidement traduit. 